\title{
PROSE COMPREHENSION BEYOND THE WORD REVISITED
}

Rolf A. Zwaan

Erasmus University Rotterdam

Rolf A. Zwaan

Department of Psychology, Educational, and Child Sciences

Erasmus University Rotterdam

zwaan@essb.eur.nl 
A perennial puzzle in the study of language comprehension is to account for the phenomenological "richness" of comprehension, or "prose comprehension beyond the word" to use the title from Art Graesser's (1981) book. The stripped-down contexts and minimalist stimuli of the typical psychological experiment cannot do justice to this richness (Graesser, 1981; Graesser, Millis, \& Zwaan, 1997). Various attempts have been made over the years to look behind the façade of words (see Zwaan, 2016 for a recent review).

The current chapter is inspired by the type of conversation I remember having on multiple occasions with Art Graesser, for example, when staying at his house in Rolling Oaks in Memphis, at the Winter Text conference in Jackson Hole, Wyoming, or on various car trips through the Netherlands and Belgium, or Alabama and Georgia. Such conversations would usually start with Art asking, seemingly out of the blue, a question like: "So what does a perfect monster look like to you?" After some moments of puzzlement, a lively and stimulating discussion would usually ensue, and new ideas would often emerge. This is my attempt to emulate such a conversation. As was usually the case with these conversations, the ideas that would come up would be a cocktail of conventional knowledge, far-fetched speculations, and maybe some good novel insights also thrown into the mix. I hope this chapter will produce a similar blend.

What lies beyond the word?

I am imagining that Art is asking me: "So what lies beyond the word when we read a story?" A good start to answering this question is to deconstruct it. The underlying metaphor is that words are simply a façade that we need to look behind to see what's really going on. But that's not really how language works, of course, as I am sure Art would agree (I took the liberty of overinterpreting his title for rhetorical purposes). Far from being a pretty useless piece of veneer, language is a set of instructions to what lies behind. 
What lies behind, though? At a first approximation, language provides pointers to knowledge and experiences that we can reconstruct from long-term memory. So when comprehenders - be it a reader who grabs a book from the shelf or activates their e-reader, or a listener starting their audiobook-engage with a story, they bring to bear their knowledge and experiences. This idea permeates all theories of comprehension and is thus uncontroversial. However, it is not so easy to determine what kind of information gets activated and much research has been devoted to this question. In his 1981 book, Art reviewed concepts from the artificial intelligence literature that were common at the time, such as frames and scripts. Later ideas involved situation models and mental simulations. The idea of long-term memory as a resource for (re)constructing knowledge and experiences, semantic and episodic (which included autobiographical) memory, respectively, captures the idea that much knowledge is shared but some experiences are highly individual. Still both are likely to get activated when comprehending a story, although the empirical research has mostly focused on the activation of shared representations, whereas individualized representations have largely been ignored (presumably because they are far more difficult to investigate).

So words are cues to shared and individual knowledge and experiences. The activated knowledge and experiences form the building bricks of comprehension. Again, I'm not saying anything new here, although this claim is probably a bit less uncontroversial than the previous one. The key issue, however, is that there is something missing from this picture. The activation of knowledge and experiences is not a goal in itself. Rather, it is a means to an end. That end, in much of prose comprehension at least, might seem to be a vicarious experience of the events that are related by the story. The objective of someone who writes or tells a story is not merely to activate in the comprehender a set of knowledge units and experiences, the goal is to let that person experience in some way the situation that is being described. 


\section{Vicarious experience}

The phrase "in some way" is operative here. Let's consider the extremes. At one extreme is the person to whom the words remain a façade. This person is not able to progress beyond them. One does not have to be diagnosed with a severe reading problem to become stuck at the word level. We all are grasping at semantic straws when we try understand a story in a language in which we have limited proficiency. In such cases, only shards of knowledge or experience might be activated. When listening to a story in a foreign language, we might be thinking something like: "Okay, so this story is about a woman who is having some argument with her husband and then something bad happens. No idea what the argument is about or what the something bad is, though..."

Often the experiences that are activated will be, at best, a subset of all the experiences that could potentially be activated or that might maximize overlap with the story. For example, I hardly know anything about cricket. So when I try to comprehend a story about people playing the game, I am handicapped by the limited overlap between my repertoire of experiences and the described actions. But I have played other team sports. So even though I might not have an experience of being at bat (is that what it's called?) in a cricket match that I can rely on to understand the story, I might activate-which of course is shorthand for saying "reading/listening to the story activates in my brain"--more broadly relevant experiences, for example being at bat in a softball game, or being on the losing team. In this case, my comprehension would be less precise than it would be if I had a lifetime of cricket experience to bring to the story. Nevertheless, it would be wrong to say that I didn't understand the story at all. I just didn't understand it very deeply.

At the other extreme is the comprehender who vicariously experiences everything that is being described. I don't think such an individual exists. Extreme vicarious experiencing would be a life-threatening condition, one would think. After all, the most harrowing experiences are 
described in stories. It cannot be healthy to experience all of them, even if vicariously. Although most people will have the experience of sometimes making kicking movements when watching a soccer match, it is clear that an abundance of such empathic responses would not be adaptive; they might be downright dangerous. Extreme immersion in the story world would also be likely to turn someone into a social pariah. No one would want to be near someone with such lively bouts of comprehension.

So the extremes are unlikely and the degree of vicarious experience likely depends on a number of factors associated with the comprehender, including: (a) language and discourse skills (e.g., about the genre of the text), (b) background knowledge, (c) story-relevant experiences, and (d) motivation to comprehend. It is evident that these factors are not unrelated. For example, there is a relation between language skills and background knowledge. After all, language itself is an important medium for acquiring background knowledge and in turn, having more background knowledge facilitates language comprehension. Likewise, motivation is related to the other factors. A lack of relevant language skills, background knowledge, and/or relevant experiences is likely to make someone less motivated to comprehend a story. However, even comprehenders with a richly stocked arsenal of relevant skills, knowledge, and experiences, might still vary for any number of reasons in the degree to which they are motivated to engage with a story.

The depth of immersion in the story world also depends on aspects of the story itself, such as (a) the writing style, (b) the perspective from which an event is described, (c) the position of the event in the story. Of course, these factors also interact with comprehenderrelated factors. For example, when engaging with a story, it takes the comprehender a while before he or she has built up the story world. In other words, in the process of comprehending, the comprehender is acquiring relevant (to the story world) knowledge and this knowledge can be activated during subsequent processing, thereby facilitating the comprehension process. It is 
not my goal here to give an exhaustive summary of the factors and their interactions that might impact degree of immersion in a story world. Rather, my goal is merely to set up an argument.

Let's assume that all of the factors I just mentioned conspire to give the comprehender the optimal vicarious experience. Would this count as "deep" comprehension? I am going to explain why it doesn't.

Granted, immersion in the story world is certainly a deeper form of comprehension than merely understanding some words in the sentence or even than knowing all the words but not having the relevant experiences and knowledge to bring to the table. On the other hand, most stories are more than merely vehicles for triggering vicarious experiences. Consider even the lowly joke. The point of a joke is not merely to provide the listener with a vicarious experience. Rather the point (one of the points at least) is to elicit a response from the listener: laughter about the described situation. In addition, the jokester likely has social goals, such as bonding.

However, I want to make a broader point here and to make it, I am going to maximize common ground by relying on the reader's familiarity with one of the most popular stories of the past decade: Game of Thrones. Game of Thrones is both the title of the first in an ongoing series of novels, A Song of Ice and Fire, by George R.R. Martin, and the name of a TV series that covers the entire series of novels published thus far as well as continuing the story beyond the novels. The story is set in a medieval fantasy world. I will use Game of Thrones to illustrate two additional aspects of story comprehension that lie beyond immersion and that I propose represent deep comprehension: internal projections and outward projections. Internal projections connect events within the story world. Outward projections connect the story to a social, cultural, and historical context.

Internal and outward projections

In the beginning of Game of Thrones (the novel and the TV show), a nobleman named Ned Stark is making his young son watch while he decapitates a traitor. The reader/viewer doesn't know this yet, but this foreshadows Ned's own beheading later on (albeit that he was 
unjustly convicted of being a traitor). This happens in the first book of the series and the first season of the TV show, so relatively early in the story. I propose that recognizing the link between the two events is a step towards deep comprehension. Importantly, however, simply being reminded of the earlier decapitation is not sufficient. The comprehender has to realize that the author wants the comprehender to identify the foreshadowing. It enhances the coherence of his story. Moreover, it suggests the importance of foreshadowing in the story in general, perhaps prompting the reader/viewer to anticipate more instances of foreshadowing as the story unfolds.

There is ample evidence that comprehenders of the TV show and books are eager to discover instances of foreshadowing. There are many web forums devoted to Game of Thrones (as well as to many other stories). An example is the Reddit forum "Game of Thrones, a Reddit of Ice and Fire" (https://www.reddit.com/r/gameofthrones/). There are thousands of comments in which enthusiasts (and non-enthusiasts) of the story exchange speculations about upcoming events.

An early theory of book readers--the first book in the series was published in 1995--was that one of the main characters of the story, Jon Snow, is not the bastard son of Ned Stark as everyone in the story world (including Jon Snow himself) believes him to be. Rather, he is Ned Stark's nephew, being the son of his sister, Lyanna Stark. More importantly (for the story), he is the son of Rhaegar Targaryen, who was heir to the throne of the entire continent of Westeros. This makes Jon not a second-class citizen in his own family but the de facto heir to the throne (both his parents were murdered just after he was born). In the final episode of Season 7 of the TV show (which has by now far outpaced the novels in terms of story development), which aired in July 2017 , this theory was finally, after 22 years of speculation by readers, confirmed by two characters in the story. That is, they had discovered evidence of Jon's parentage.

Fans of the books and show, such as those active on the Reddit forum, are prolific at generating new hypotheses, for example about instances of foreshadowing. They do this while 
rereading the novels or re-watching the show. Here is an example that I found within a minute of searching on the Reddit forum. The example comes from someone rewatching the first episode of the TV show: "First time I'm noticing Robert's Curse: He touched Ned, Catelyn, Robb and Rickon while greeting them and they all died. He didn't touch Sansa, Arya, Jon and Bran and they all still live. Coincidence or Foreshadowing?" To explain, Robert is the king of Westeros and Catelyn, Robb, Rickon are the wife and sons of Ned. All, including Robert, are brutally killed in the TV show (though not (yet) in the books. The other characters are still alive after Season 7 of the TV show, which is when the Redditeer formulated his hypothesis.

This example brings up an important point. Deep comprehension might not be achieved on the first reading or viewing but might instead require repeated exposure to the story, although it is an interesting empirical question to what extent comprehenders achieve feats of deep comprehension during a first exposure. It likely depends on experience with the genre in general and with the story in particular, which is a testable prediction.

No one will think me unfair when I state that the bulk of language comprehension research is targeted at the first exposure to a story. In part, this is because of the use of what Graesser (1981) called "single response measures." Examples of these methods include keypress tasks by which subjects move through the text word-by-word or sentence-by-sentence, eye tracking methods, in which subjects typically see one line of text at a time while their eye movements are being recorded, and event-related potential methods, in which the electrical responses in the brain to text are being measured while the subject processes text one word at a time.

This means that most, though certainly not all, of the empirical evidence that we have of comprehension actually represents a thin slice of the entire process. For example, the nature of the experimental task often prevents subjects from going back in the text. Again, I'm not saying anything new here. It will be common knowledge to any high school student that multiple readings of a text usually lead to better understanding. Nevertheless, the point remains that 
cognitive psychological research has mostly focused on comprehension processes at the shallow end of the pool and that, consequently, we have a skewed view of the comprehension process, underestimating the lengths comprehenders might go to achieve a fuller understanding. As the Reddit example shows, many people enjoy engaging with the story world on repeated occasions.

I have argued that people enjoy uncovering internal projections, such as instances of foregrounding. Discovering these may enhance not only enjoyment but may also enhance appreciation of the author, who, after all, took the effort to put in all the foreshadowing. In other words, discovering the devices that the author implemented to enrich the message enhances appreciation for the construction of the message. Uncovering literary devices, of course, has been the province of literary criticism at least since the Russian Formalists, but the activity on so many internet forums shows that it is currently enjoying broad popularity. My point here is that uncovering the devices with which the narrative experience is orchestrated can be viewed as a form of deep comprehension. First, there is the processing of the words, then there is the mental construction of the story world, and beyond this lies the appreciation for the devices that give rise to the narrative experience.

Note also that device-related inferences, such as those involving foreshadowing, sometimes serve to enhance the overall coherence of the mental representation. Some story events cannot be easily explained by only considering factors within the story world but can be explained when the story is considered as a message animated by a set of devices. Again, Game of Thrones serves as a natural example. Especially in Season 7 of the TV show, viewers are complaining about characters' ability to travel across the medieval-like continent of Westeros in unrealistically short spans of time. Being in the fantasy genre, Game of Thrones naturally has several unrealistic elements--some magic, a few dragons, an army of the dead-but unexplained prodigious traveling speed is normally not one of them. 
How then to explain some characters' ability to zip across the continent and always arrive at the right time and place to lend a helping hand in a fight or deliver a clever retort in a conversation? The answer comes from regarding the show as a construction. For the story to move forward it is necessary that certain characters are on hand at the right time. It so happens that their presence is sometimes required in distant locations at relatively short time intervals. So the show's producers, who are more constrained than the author of the sprawling novels due to the format and budget constraints, are faced with a problem. How do we get Character A from location $X$ to location $Y$ on the other end of the continent? They have decided to solve this problem by cutting corners on travel times. So in this case, a coherent interpretation is achieved by taking into account the production of the story. Of course, this focus on the use of narrative devices may also lead some to develop a negative evaluation of the story, namely as a poorly constructed one. This is perhaps why there are people on forums who are fervently trying to explain away inconsistencies from within the story world, for example by providing speculative calculations meant to show that the travel times are not unrealistically short. These attempts are motivated by a desire to keep the story coherent.

Internal projections by themselves are not characteristic of deep comprehension. They become characteristic of deep comprehension when they are followed by an outward projection, in this case a projection internal to the story world (e.g., noticing an instance of foregrounding) followed by a projection outside the story world, in this case to the communicative context: an appreciation of the author's use of narrative devices. So it is the sequence of moves, internaloutward that represents one form of deep comprehension.

Outward and inward projections

Deep comprehension can also start with an outward projection. For example, Game of Thrones is loosely based on an actual historical series of events, the Wars of the Roses, which took place in England in the 15th century. George R.R. Martin has left clues in his story about its connection with the historical events (e.g., in the names of two of the noble houses involved 
(Lannister vs. Lancaster and Stark vs. York) and their colors (red and white). These allusions can be interpreted as invitations to the comprehender to consider parallels between the story and the historical events. As such, they serve to embed the story in a larger (historical) context.

It should be noted, however, that there are also many instances in which a story is projected outward without much license from the text or author. Taking (part of) a story as allegorical is a way of projecting outward from the story. For example, it is tempting to view Game of Thrones as an allegory of the climate change debate. There is a major threat to the world, "winter is coming" is the motto of House Stark and makes frequent occurrences in the story, but rather than giving it serious consideration, the noble houses of Westeros initially waste a great deal of time battling each other. This has been seen by many as a parallel to the climate change debate. To be fair, though, by the end of the 7th season of the TV show, all major characters seem convinced of the looming threat beyond their borders. The same cannot be said about some participants in the climate change debate.

Such outward projections are food for endless speculation; just type in the search string "climate change game of thrones" into Google to get an impression. If an outward projection is to be regarded as deep comprehension, I propose that the first criterion is that it needs to be licensed in some way by the text or by the author.

Relying on authorial intent for the interpretation of text is suspect in certain branches of literary criticism but I would nevertheless maintain that when it is impossible or unlikely that the author has intended the story as an allegory, that allegorical interpretation does not constitute deep comprehension. For example, when it is obvious that the author could not have intended a particular allegorical interpretation, and when the textual evidence (e.g. in the form of allusions) is tenuous, the outward projections might qualify as over-interpretations.

In his famous story "Pierre Menard, Author of the Quixote," Jorge Luis Borges provides a nice thought experiment of how knowledge about the author's background colors comprehension processes. Borges describes a fictional eccentric 20th-century French writer, 
called Pierre Menard, who writes a verbatim replication of Cervantes' 1602 novel. However, when viewed as an original work by the 20th century French author, the work acquires a very different meaning because now it is understood against the background of what transpired in the four centuries since Cervantes. The connections between the Quixote and this new worldknowledge is of course not something Cervantes could have intended, so projections from Cervantes to, say Twentieth Century events clearly cannot be regarded as representing deeper comprehension of his Quixote. When we view Menard as the author, such projections would make sense. (By the way, my use of Borges' story here is itself an example of an outward projection.)

Thus, nothing prevents comprehenders from making outward projections, but some projections are more consistent with the context in which a story was written than others. So should outward projections be considered deep comprehension? The first important thing to observe is that outward projections do not enhance comprehension of the story itself. Rather, they are projections from the story to a new situation (much like the way I used the Menard example in the context of this chapter to make a point about deep comprehension). For outward projections to yield deep comprehension of a story, they need to feed back into the story world. Indeed, outward projections can have reciprocal effects on the comprehension of the story world. This occurs, for example, when there are certain events or connections between events in the target domain (e.g., the Wars of the Roses) that provide clues about the relations between events in the source domain (Game of Thrones). Such inferences would then deepen the understanding of the source story. This process can be characterized as an outward projection followed by an inward projection.

Internal projections, such as noticing foreshadowing, might give rise to outward projections, for example about the author's use of narrative devices. This requires stepping out of the story world. Conversely, as described in the previous paragraph, outward projections, such as noticing an allegorical relation, can feed back into the story world via inward projections. 
In fact, it is only when these sequences of projections are produced that deep comprehension can be said to occur.

Is immersion necessary/sufficient for deep comprehension?

Now that I have defined deep comprehension, the question we can ask is: is immersion in the story sufficient and/or necessary for deep comprehension? This is an important question to address because if it receives an affirmative it means that immersed comprehension is the gateway to deeper comprehension. If, on the other hand, the question receives a negative answer, then it means that a separate mechanism needs to be identified to account for deeper comprehension separate from immersed comprehension.

Let us start with internal-outward projections. The example I have provided was that of a reader/viewer (1) noticing the parallel between Ned beheading a traitor and Ned being beheaded as a traitor himself and (2) appreciating the author's use of this narrative device. So the question before us is: would immersion facilitate these processes? There is reason to think it does and it doesn't. Immersion can be viewed as a form of elaboration, which should lead to a deeper, more elaborate encoding of the scene. This, in turn, should lead--according to pretty much every theory of memory--to a higher retrieval likelihood. As a result, the representation of the first beheading should stand a better chance of being reactivated during the viewing of the second beheading when the reader was immersed in the story. Although depth of immersion might help the comprehender being reminded of the earlier beheading when watching or reading about the second one, it is important to emphasize that this is only the first step. What is needed at this point is the appreciation that the author put the foreshadowing in on purpose. Here, it is possible to predict that immersion might, in fact, hinder the forming of an outward projection. After all, by definition, an outward projection requires stepping out of the story world and viewing the story as a communicative act. The more immersed a comprehender is, the more difficult it might be to take this step. 
If immersion is not sufficient for internal-outward projections, is it then at least necessary? As I said earlier, immersion during the processing of the first event should increase the likelihood that that event will be retrieved on a later occasion. This seems uncontroversial. The necessity question, however, is not a question of degree but is categorical in nature. Something either is or is not necessary. It is an empirical question when considering first-time comprehension. It would require being able to determine whether or not a comprehender is immersed in the story at a given point and then examining the likelihood of reminding the earlier event when a later event is processed. In the absence of empirical evidence, I am going to speculate that immersed comprehension is not necessary for internal projections. At this point, it cannot be ruled out that internal projections are based on shallow processing, for example, based on rudimentary representation of a situation (much like my representation of the cricket story).

There is another issue to consider. We might say that immersion leads to being invested in the story world. Therefore, people who are immersed in the story world are likely to fall victim to motivated reasoning and seek explanations for apparent inconsistencies (such as impossibly short travel times) within the story world (as people on the Reddit forum have attempted with regard to Game of Thrones). People who are less invested in the story world, on the other hand, will tend to seek for explanations at the level of the use of narrative devices. It should be possible to test this idea empirically.

How about outward projections? I note first that outward projections are not necessarily indices of deep comprehension, unless there are sufficient cues. Placing a story in its historical context is a prime example of an outward projection. I already mentioned that immersion is neither necessary nor sufficient for this. For example, the realization that Shakespeare's Romeo and Juliet shares a theme with Ovid's Pyramus and Thisbe does not seem more likely if someone really empathizes with the Bard's star-crossed lovers than if they take a more dispassionate stance toward the story. One could say, though, that having been immersed in a 
story and having become invested in the story world provides the motivation to look for deeper meaning. In this sense, immersion may have an indirect effect on deep comprehension. It could also be argued that although immersion would seem to work against outward projections, it is more consistent with inward projections (importing information into the story world). However, you first need to be outside the story world before you can have an inward projection.

\section{Conclusion}

My main conclusions from this thought experiment are that internal-outward and outward-inward projections can, when sufficiently supported, be considered forms of deep story comprehension. Immersion in the story world, itself already a form of comprehension that is deeper than what is often studied in the psychological laboratory, is neither sufficient nor necessary for internal and external projections to occur, although it might play a role in heightening the motivation to form internal-outward and outward-inward projections.

So this is how I might have answered Imaginary Art's question of what lies beyond the word. What l've said is a cocktail of common knowledge, novel ideas, and perhaps farfetched speculations, much like how I must have responded to Art's questions in the past, although the present account is, hopefully, somewhat more coherent than my ramblings at the time. 


\section{References}

Graesser, A. C. (1981). Prose comprehension beyond the word. New York: Springer.

Graesser, A.C., Millis, K.K., \& Zwaan, R.A. (1997). Discourse comprehension.

Annual Review of Psychology, 48, 163-189.

Zwaan, R.A. (2016). Situation models, mental simulations, and abstract concepts in discourse comprehension. Psychonomic Bulletin \& Review, 23,1028-1034, doi:10.3758/s13423-015-0864-x. 